\title{
Validation of national genetic evaluations for maternal beef cattle traits using Irish field data
}

\author{
N. McHugh, $* 1$ A. R. Cromie, $\dagger$ R. D. Evans, $\uparrow$ and D. P. Berry* \\ *Teagasc, Animal and Grassland Research and Innovation Centre, Moorepark, Fermoy, Co. Cork, Ireland; \\ and $†$ Irish Cattle Breeding Federation, Highfield House, Shinagh, Bandon, Co. Cork, Ireland
}

\begin{abstract}
Genetic evaluations provide information to aid in breeding decisions that increase long-term performance of animals and herds. However, to date no study has been undertaken to investigate the accuracy of the Irish maternal genetic evaluations in beef cattle. The objective, therefore, of this study was to quantify the relationship between phenotypic performance and measures of genetic merit for predominantly maternalrelated traits in Irish beef cattle. The association between animal EBV for calving interval, age at first calving, and both direct and maternal weaning weight with the respective phenotypic performance was quantified using a fixed effects model; the expectation for the regression coefficient of phenotypic performance on EBV was one. The association between genetic merit for cow survival, perinatal mortality, calving assistance, and calving dystocia with the log of the odds of the respective trait was quantified using logistic regression. The association analyses were conducted using field data on up to 38,619 records from 5,236 herds. Age at first calving
\end{abstract}

increased linearly by $0.32 \pm 0.15(P=0.03)$ days per day increase in EBV for age at first calving. Calving interval increased by, on average, $0.58 \pm 0.16(P=0.002)$ days per day increase in EBV for calving interval although the association differed by parity with a greater association in pluriparae. Weaning weight increased linearly by $1.74 \pm 0.09$ and $0.84 \pm 0.16 \mathrm{~kg}(P<0.001)$ per kilogram increase in EBV for direct and maternal weaning weight, respectively. The log of the odds of a cow surviving to next lactation increased linearly by $0.16 \pm 0.03$ $(P<0.001)$ per unit increase in EBV for cow survival. The log of the odds of an assisted calving or dystocia both increased linearly by $0.21 \pm 0.01$ and $0.24 \pm 0.01$, respectively, per unit increase in EBV for direct calving difficulty $(P<0.001)$. The log of the odds of a dead calf at birth increased linearly by $0.93 \pm 0.13(P<0.001)$ per unit increase in EBV for calf mortality. Results from this study show that selection of breeding animals for favorable maternal genetic attributes will result in favorable improvements in performance and profitability.

Key words: beef, genetic evaluations, maternal traits

J. Anim. Sci. 2014.92:1423-1432 doi:10.2527/jas2013-6658

\section{INTRODUCTION}

Genetic evaluations provide information to aid in breeding decisions that increase long-term performance of animals and herds. Genetic gain is a function of how accurately the genetic evaluations reflect the true breeding value of an animal and how these EBV manifest themselves as differences in phenotypic performance. Assessment of how genetic evaluations reflect differences in phenotypic performance can be undertaken using

\footnotetext{
${ }^{1}$ Corresponding author: noirin.mchugh@teagasc.ie

Received May 1, 2013.

Accepted February 10, 2014.
}

controlled experiments of animals divergent for genetic merit (Minick et al., 2001; Campion et al., 2009; Coleman et al., 2010) or regressing genetic merit on individual animal (Marshall and Long, 1993; Mee et al., 2008, 2011) or herd-level (Ramsbottom et al., 2012) phenotypic performance using field data. Previous assessments of the accuracy of genetic evaluations for terminal and maternal traits, either as separate traits (Minick et al., 2001; Thrift and Thrift, 2006; Campion et al., 2009) or as a breeding goal (MacNeil, 2003; Clarke et al., 2009), indicate that differences in animal performance reflect differences in animal genetic merit. Although previous studies have examined the accuracy of beef genetic evaluations for maternal milk yield (Diaz et al., 1992; Miller 
and Wilton, 1999; Brown et al., 2005), to date, however, no such study has been undertaken using a combination of maternal traits but especially for fertility traits.

Performance statistics of the Irish national beef herd clearly show considerable scope for improvement. Irish cows on average calve for the first time at approximately 30 mo of age, with a mean calving interval of $384 \mathrm{~d}$ (Berry and Evans, 2014), and produce only 0.85 calves per year (A. R. Cromie, Irish Cattle Breeding Federation, Bandon, Co. Cork, Ireland, personal communication). Nevertheless, access to accurate maternal genetic evaluations could aid producers in selecting superior bulls and cows for breeding, thereby improving the maternal efficiency of the beef sector. The objective of this study, therefore, was to quantify the relationship between phenotypic performance and measures of genetic merit for maternal-related traits in Irish beef cows.

\section{MATERIALS AND METHODS}

\section{Phenotypic Data}

Phenotypic performance data from Irish beef herds recorded between April 2011 and August 2012 were extracted from the Irish Cattle Breeding Federation (ICBF) database; information necessary for the calculation of cow survival (discussed later) were extracted from the ICBF database between March 2010 and August 2012. Information on associated environmental factors (e.g., calving dates, herd of calving, cow parity) and animal pedigree was also available.

Phenotypic traits considered in the analysis included age at first calving, calving interval, survival to the next lactation, degree of calving difficulty, perinatal mortality, and weaning weight. The data consisted of both crossbred $(95 \%$ of the data) and purebred (5\% of the data) beef animals. Only beef animals classified as $>66 \%$ beef blood were retained. Aberdeen Angus, Belgian Blue, Charolais, Hereford, Limousin, and Simmental breeds represented the breed fractions in both the crossbred and purebred animals in the dataset. Holstein-Friesian bloodlines also existed in most of the crossbred animals because of the use of crossbred dairy $\times$ beef females as commercial beef cows (Berry et al., 2006).

Reproductive Performance and Survival. Calving dates from 877,781 calving events were available from 43,847 beef herds. Age at first calving, calving interval, and survival phenotypes were defined as outlined in detail by Berry and Evans (2014). Age at first calving was defined as the number of days between birth and first calving; only age at first calving records between 660 and 1,278 d were retained, consistent with the edits performed in the national genetic evaluations (Berry and Evans, 2014). Calving interval was defined as the num- ber of days between 2 consecutive calving events for the same cow. Only calving interval records between 300 and $800 \mathrm{~d}$ were retained, consistent with the edits undertaken in the national genetic evaluations.

Survival to next lactation (binary trait) was defined as whether or not a cow survived from lactation $i$ (calved between March 2010 to March 2011) to lactation $i+1$ (April 2011 to August 2012). A cow was assumed not to have survived if: 1) no calving record existed between the April 2011 and August 2012 period or 2) if the cow was slaughtered or died on farm within $400 \mathrm{~d}$ of calving between March 2010 and March 2011.

Only records from parity 1 to 10 cows were retained and parity was categorized as $1,2,3,4$, and $\geq 5$. For all 3 traits evaluated, only records from cows with a known sire and maternal grandsire were retained; the latter edit resulted in discarding a large proportion (57 to $70 \%$ ) of the data due to poor recording of male parentage in commercial animals.

Herd-year-season contemporary groups were generated for each trait separately using an algorithm described by Crump et al. (1997). This algorithm creates contemporary groups based on animals from the same herd calving in close proximity of time. In this study, animals from the same herd that calved within $10 \mathrm{~d}$ of each other were grouped together. If the number of records in this immediately defined contemporary group was less than 8 , then this contemporary group was merged with an adjacent group if the start date of one group and the end date of the other group were within $182 \mathrm{~d}$ of each other. For age at first calving the contemporary group was defined as herd-year-season of service as a nulliparae and was based on the herd of service where the heifer resided 9 mo before calving. Only heifers remaining in the same herd from 9 to 15 mo before first calving were included in the analysis. For calving interval and survival the contemporary group was defined as herd-yearseason of calving. For survival, to avoid quasi-complete separation of the data in the subsequent analysis, only contemporary groups with variation were retained. For all traits, only contemporary groups with at least 5 records were retained consistent with the edit applied in the national genetic evaluations of these traits.

Following all edits 7,981 records for age at first calving, 43,067 records $(38,619$ cows) for calving interval, and 5,582 records for survival remained (Table 1).

Calving Performance. Calving difficulty in Irish beef and dairy cows is subjectively scored by producers on a scale of 1 to 4 as no assistance/unobserved, slight assistance, severe assistance, or veterinary assistance. In the present study, calving difficulty scores were dichotomized into 2 binary traits: 1) calving assistance and 2) calving dystocia. Calving assistance was defined as cows that required any assistance (slight, severe, or veterinary assistance $=1$ ); cows that calved unobserved or required no as- 
Table 1. Number of animals, contemporary groups (CG), herds, dams, sires, and maternal grandsires (MGS) file for each trait

\begin{tabular}{|c|c|c|c|c|c|c|}
\hline Trait & No. of animals & No. of CG herd-year-season & No. of herds & No. of dams & No. of sires & No. of MGS \\
\hline Age at first calving & 7,981 & 1,106 & 982 & 7,635 & 2,123 & 2,755 \\
\hline Calving interval & 38,619 & 5,236 & 3,738 & 31,893 & 7,959 & 6,570 \\
\hline Calving assistance & 25,967 & 2,911 & 2,397 & 25,967 & 3,741 & 6,059 \\
\hline Calving dystocia & 12,770 & 1,383 & 1,217 & 12,770 & 2,093 & 3,472 \\
\hline Calf mortality & 19,547 & 1,800 & 1,597 & 19,547 & 2,615 & 5,659 \\
\hline
\end{tabular}

sistance were coded separately (assistance $=0$ ). Calving dystocia was defined as cows requiring severe assistance or veterinary assistance $($ dystocia $=1)$; cows that were recorded with no assistance/unobserved or slight assistance were coded separately $($ dystocia $=0)$. In Ireland, perinatal mortality is defined as a calf dead at birth or within $24 \mathrm{~h}$ of birth (mortality $=1)$; calvings where no mortality was recorded were coded separately (mortality $=0$ ).

For all calving performance traits (i.e., dystocia, assistance, and perinatal mortality), only singleton calves with a known sire, dam, and maternal grandsire were retained for analysis. Records for calving dystocia and assistance where the maternal grandsire of the dam (i.e., the calf's great maternal grandsire) was unknown were also omitted from the analysis. Only parity 1 to 10 dams were retained and parity number was categorized as $1,2,3,4$, and $\geq 5$.

Contemporary group for the calving performance traits was defined as herd-year-season of calving separately for each trait using the algorithm described previously. Only contemporary groups with at least 1 recorded incidence of calving assistance, dystocia, or calf mortality were retained for the analysis of that trait. Contemporary groups with less than 5 records were omitted. Following all edits, 25,967 calving events with calving assistance information, 12,770 calving events with recorded dystocia information, and 19,547 calving events with perinatal mortality information remained (Table 1); the difference in number of records for calving assistance versus calving dystocia was due to the restriction of at least 1 incidence of the trait under investigation to exist within the contemporary group.

Weaning Weight. A total of 160,062 weaning weight records on 150,894 animals from 19,054 herds were available. Weanlings were defined as male and female cattle aged between 6 and $12 \mathrm{mo}$ at the time of weighing. Only singleton weanlings weighing between 150 and $600 \mathrm{~kg}$ were retained. Only the first record in time per weanling was retained. Weight records from weanlings with no known dam, sire, or maternal grandsire were discarded. A large proportion (57\%) of weanlings was omitted from the data due to poor recording of male parentage in commercial animals. For weaning weight, contemporary groups of herd-year-season of weigh- ing were generated using the algorithm previously described. Similar to the national genetic evaluation edits, only contemporary groups with at least 5 records were retained. Following all edits 10,878 weaning weight records remained (Table 1).

\section{Genetic Information}

Predicted transmitting ability (PTA) records for all male animals from the March 2011 Irish domestic genetic evaluations were available. Therefore, phenotypic information used to validate the genetic information in the present study did not contribute to the genetic evaluations and therefore no environmental covariance existed between the 2 data sources. Predicted transmitting ability for the traits used in the analysis included age at first calving, calving interval, cow survival, direct and maternal calving difficulty, direct perinatal mortality (PTA for maternal perinatal mortality are not estimated), and direct and maternal weaning weight.

The ICBF, responsible for the national beef genetic evaluations in Ireland, undertakes 6 routine evaluations 3 times a year (i.e., April, August, and December) for each of the suites of traits: calving performance, beef performance, live-animal linear scores, docility, milkability, and cow fertility. The evaluations are based on a multibreed population and are undertaken in MIX99 (Lidauer et al., 2011). Multitrait genetic evaluations are undertaken within each suite of traits (i.e., genetic evaluations for age at first calving, calving interval, and survival are undertaken in a single multitrait animal model genetic evaluation). The majority of Irish suckler cows are crossbred and hence all evaluations adjust for the heterosis and recombination loss coefficient of the animal. There is a substantial level of transfer of genetic material between Irish dairy and beef herds where pedigree beef natural mating bulls are frequently used as natural service sires in dairy herds. Additionally, commercial beef dams originate as beef sired females from dairy herds (Berry et al., 2006). Therefore, genetic evaluations for calving and carcass performance traits use both beef and dairy herd data. Further details on the ICBF genetic evaluations are in Evans et al. (2007, 2008, 2009). Trait 
Table 2. Phenotypic, heritability estimates used in the national genetic evaluations, and EBV (direct and maternal) mean $(\mu), \mathrm{SD}$, and range for each trait

\begin{tabular}{|c|c|c|c|c|c|c|c|c|c|c|c|}
\hline \multirow[b]{3}{*}{ Trait } & \multirow{2}{*}{\multicolumn{3}{|c|}{ Phenotypic }} & \multirow{2}{*}{\multicolumn{2}{|c|}{ Heritability }} & \multicolumn{6}{|c|}{ EBV } \\
\hline & & & & & & \multicolumn{3}{|r|}{ Direct } & \multicolumn{3}{|r|}{ Maternal } \\
\hline & $\mu$ & SD & Range & Direct & Maternal & $\mu$ & SD & Range & $\mu$ & $\mathrm{SD}$ & Range \\
\hline Age at first calving, $d$ & 950 & 152 & 660 to 1,278 & 0.31 & - & -4.29 & 12.00 & -75.78 to 29.68 & - & - & - \\
\hline Calving interval, $\mathrm{d}$ & 379 & 58 & 300 to 799 & 0.02 & - & -1.23 & 2.35 & -9.36 to 7.37 & - & - & - \\
\hline Survival, \% & 78 & 0.41 & 0 to 1 & 0.02 & - & -0.29 & 0.98 & -3.10 to 3.61 & - & - & - \\
\hline Calving assistance, $\%$ & 31 & 0.46 & 0 to 1 & 0.10 & 0.02 & 5.16 & 2.48 & 0.58 to 20.58 & 5.18 & 1.35 & 1.33 to 16.34 \\
\hline Calving dystocia, $\%$ & 18 & 0.38 & 0 to 1 & 0.10 & 0.02 & 5.36 & 2.54 & 0.62 to 20.58 & 5.16 & 1.41 & 1.33 to 16.34 \\
\hline Calf mortality, \% & 11 & 0.23 & 0 to 1 & 0.04 & - & 0.43 & 0.27 & -0.97 to 1.98 & - & - & - \\
\hline Weaning weight, $\mathrm{kg}$ & 341 & 70 & 152 to 598 & 0.26 & & 3.54 & 6.74 & -15.69 to 27.89 & 0.78 & 3.69 & -12.73 to 15.73 \\
\hline
\end{tabular}

heritability estimates used in the national genetic evaluations are in Table 2.

For the 3 cow fertility traits (age at first calving, calving interval, and survival), the EBV of each cow was defined as the sum of the sire PTA and one-half the maternal grandsire PTA. Similarly for direct calving difficulty, perinatal mortality, and direct weaning weight, the EBV of each calf was estimated as the sum of the respective sire PTA plus one-half the maternal grandsire PTA. For maternal calving difficulty the EBV of the dam (i.e., maternal effect) was calculated as the sum of the dam's sire PTA plus one-half the dam's maternal grandsire PTA. Due to low levels of ancestry recording in the dams of animals with weaning weight records, the EBV of the dam for maternal weaning weight was calculated as the dam's sire PTA only.

Heterosis and recombination loss coefficients for each animal (and dam for maternal effects) were calculated as

$$
\begin{aligned}
& 1-\sum_{i=1}^{n} \operatorname{sire}_{i} \times \operatorname{dam}_{i} \text { and } 1-\sum_{i=1}^{n}\left(\operatorname{sire}_{i}^{2}+\operatorname{dam}_{i}^{2}\right) / 2, \\
& \text { respectively, }
\end{aligned}
$$

in which sire ${ }_{i}$ and dam $i$ are the proportion of breed $i$ in the sire and dam, respectively.

\section{Data Analysis}

Multiple regression models for each trait were created using forward-backward regression where $P=0.05$ was used as the threshold significance levels for entry and exit of variables from the model; the exception was the independent variable of genetic merit for the trait under investigation, which was always forced into the models. All estimates of genetic merit were included in the models as continuous variables. Biologically plausible interactions were also tested for significance while simultaneously ensuring that no problems of quasi-complete separation of the data existed for the binary traits.

The association between cow EBV for either calving interval or age at first calving and the respective phenotypic performance was quantified using a fixed effects model in PROC GLM (SAS Inst. Inc., Cary, NC) as

$$
Y=\mathrm{CG}+\text { Heterosis }+ \text { Recombination }+ \text { Parity }+\mathrm{EBV}+e,
$$

in which $Y$ is the calving interval or age at first calving observation, CG was the fixed effect of contemporary group, Heterosis was the fixed effect for the heterosis coefficient of the cow, Recombination was the fixed effect of the recombination loss coefficient of the cow, Parity was the fixed effect of cow parity (only included when calving interval was the dependent variable), EBV was the fixed effect of EBV for the dependent variable under investigation, and $e$ was the residual effect $(\mathrm{N}(0, \mathrm{I}$ $\left.\sigma_{e}^{2}\right)$ ).

The log of the odds of a cow surviving to next lactation was modeled using logistic regression in PROC GENMOD (SAS Inst. Inc., Cary, NC) while accounting for the binomial distribution of the errors as

$$
\begin{aligned}
& \operatorname{Logit}\{P(Y=1 \mid X)\}=\mathrm{CG}+\text { Heterosis }+ \\
& \text { Recombination }+ \text { Parity }+\mathrm{EBV}+e,
\end{aligned}
$$

in which $\operatorname{Logit}\{P(Y=1 \mid X)\}$ is the log of the odds of a positive outcome (i.e., the cow surviving) given the independent variables, CG was the fixed effect of contemporary group, Heterosis was the fixed effect for the heterosis coefficient of the cow, Recombination was the fixed effect of the recombination loss coefficient of the cow, Parity was the fixed effect of cow parity, EBV was the fixed effect of EBV for cow survival, and $e$ was the residual effect.

The log of the odds of a calving assistance and a calving dystocia event was modeled using logistic regression in PROC GENMOD (SAS Inst. Inc., Cary, NC) assuming a binomial distribution of the errors as

$$
\begin{aligned}
& \text { Logit }\{P(Y=1 \mid X)\}=\mathrm{CG}+\text { Heterosis }_{\mathrm{CALF}}+ \\
& \text { Recombination }_{\mathrm{CALF}}+\mathrm{Sex}+\text { Parity }+\mathrm{Heterosis}- \\
& \mathrm{DAM}^{+} \text {Recombination }_{\mathrm{DAM}}+\mathrm{EBV}_{\mathrm{DIRECT}}+\mathrm{EBV}- \\
& \text { MATERNAL }^{+} e
\end{aligned}
$$

in which $\operatorname{Logit}\{P(Y=1 \mid X)\}$ is the log of the odds of a positive outcome given the independent variables, $C G$ was the fixed effect of contemporary group, Heterosis ${ }_{\mathrm{CALF}}$ was 
the fixed effect for the heterosis coefficient of the calf, Recombination $_{\text {CALF }}$ was the fixed effect of the recombination loss coefficient of the calf, Sex was the fixed effect of calf sex, Parity was the fixed effect of dam parity, Heterosis $_{\text {DAM }}$ was the fixed effect for the heterosis coefficient of the dam, Recombination ${ }_{\text {DAM }}$ was the fixed effect of the recombination loss coefficient of the dam, $\mathrm{EBV}_{\text {DIRECT }}$ was the fixed effect of EBV for direct calving difficulty and $\mathrm{EBV}_{\text {MATERNAL }}$ was the fixed effect of EBV for maternal calving difficulty, and $e$ was the residual effect.

The log of the odds of perinatal mortality was also modeled using logistic regression in PROC GENMOD (SAS Inst. Inc., Cary, NC):

$$
\begin{aligned}
& \text { Logit }\{P(Y=1 \mid X)\}=\mathrm{CG}+\text { Heterosis }+ \\
& \text { Recombination }+\mathrm{Sex}+\text { Parity }+\mathrm{EBV}+e,
\end{aligned}
$$

in which $\operatorname{Logit}\{P(Y=1 \mid X)\}$ is the $\log$ of the odds of a positive outcome given the independent variables, CG was the fixed effect of contemporary group, Heterosis was the fixed effect for the heterosis coefficient of the calf, Recombination was the fixed effect of the recombination loss coefficient of the calf, Sex was the fixed effect of calf sex, Parity was the fixed effect of dam parity, EBV was the fixed effect of EBV for calf perinatal mortality, and $e$ was the residual effect. The heterosis and recombination loss coefficient of the dam was not associated with perinatal mortality and was therefore not included in the model.

The association between genetic merit for direct and maternal weaning weight with phenotypic weaning weight was estimated using a fixed effect model in PROC GLM (SAS Inst. Inc., Cary, NC) as

$$
\begin{aligned}
& Y=\mathrm{CG}+\text { Heterosis }+ \text { Recombination }+ \text { Age } \times \\
& \mathrm{Sex}+\text { Parity }+\mathrm{EBV}_{\text {DIRECT }}+\mathrm{EBV}_{\text {MATERNAL }}+e,
\end{aligned}
$$

in which $Y$ is the weaning weight observation, CG was the fixed effect of contemporary group, Heterosis was the fixed effect for the heterosis coefficient of the calf, Recombination was the fixed effect of the recombination loss coefficient of the calf, Age $\times$ Sex was the interaction between calf age and calf sex, Parity was the fixed effect of dam parity, $\mathrm{EBV}_{\text {DIRECT }}$ was the fixed effect of $\mathrm{EBV}$ for direct weaning weight and $\mathrm{EBV}_{\text {MATERNAL }}$ was the fixed effect of EBV for maternal weaning weight, and $e$ was the residual effect $\left(\mathrm{N}\left(0, \mathrm{I} \sigma_{e}^{2}\right)\right)$. The heterosis and recombination loss coefficient of the dam was not associated with weaning weight and was therefore not included in the model.

For the binary traits the probability of the event occurring (i.e., cow surviving to next parity, calving assistance, calving dystocia, or calf mortality) per unit increase in the corresponding EBV was estimated using the results from the multiple regression analysis as

$$
P(X)=\left[1+e-\left({ }^{\alpha+\sum_{i=1}^{m} \beta_{i} \mathbf{X}_{i}}\right)\right]^{-1},
$$

in which $\alpha$ is the predicted intercept of the multiple regression model, $\beta$ is the predicted regression coefficient for independent variable $i$, and $\mathbf{X}_{i}$ is the associated design matrix for variable $i$. Odds ratios were calculated as the exponent of the model solutions.

\section{RESULTS}

The majority (i.e., 53\%) of calvings occurred in the spring-calving months of January to April, with a further $18 \%$ of calvings occurring during the autumn and winter months of September to December. The breed composition of the animals varied across the different datasets but, on average, more than half the animals were entirely made up of beef bloodlines. On average, dairy breeds (Holstein and Friesian mainly) accounted for approximately $20 \%$ of the breed fraction. The most common breeds were Limousin, Charolais, Simmental, Holstein, Aberdeen Angus, and Hereford. Average age at first calving was $950(\mathrm{SD}=152)$ days; the median and interquartile range was 969 and 270 $\mathrm{d}$, respectively (Table 2 ). The average calving interval was $379(\mathrm{SD}=58)$ days; the median and interquartile range was 365 and $49 \mathrm{~d}$, respectively (Table 2 ). On average, $78 \%$ of cows survived to next lactation (Table 2). The prevalence of calving assistance and dystocia across all cow parities was 31 and $18 \%$, respectively; this should not, however, be assumed to represent national statistics because an edit was applied so that each contemporary group contained some incidence of assistance or dystocia in calving performance trait under investigation. The prevalence of perinatal mortality was $11 \%$; however, similar to calving traits, to avoid quasi-complete separation of the data, only contemporary groups with some perinatal mortality were retained and therefore this should not be taken to represent national statistics. Before this edit the prevalence of calving assistance, calving dystocia, and perinatal mortality was $22.98,5.93$, and $5.48 \%$, respectively. The average weight at weaning was $341(\mathrm{SD}=70) \mathrm{kg}$ and animals were weaned, on average, at $252 \mathrm{~d}$ of age (Table 2). The average reliability of the sire's PTA ranged from 37 (calf mortality) to $73 \%$ (direct weaning weight).

\section{Calving Assistance and Dystocia}

Males calves were 2.23 times $(P<0.001)$ more likely to require assistance at birth and 2.50 times $(P<0.001)$ more likely to experience calving dystocia at birth compared to female calves (Table 3). Calving assistance and dystocia was 2.93 times $(P<0.001)$ and 3.55 times $(P<$ 0.001 ), respectively, more likely to occur in first parity dams compared to fifth parity dams (Table 3 ). 
Table 3. Gender and dam parity odds ratios (upper and lower confidence intervals in parenthesis) for calving assistance, dystocia, and calf mortality

\begin{tabular}{lcccc}
\hline \hline Trait & Level $^{1}$ & Calving assistance & Calving dystocia & Calf mortality \\
\hline Gender & Male & $2.23(2.09,2.39)$ & $2.50(2.23,2.80)$ & $1.59(1.44,1.75)$ \\
Parity & 1 & $2.93(2.65,3.24)$ & $3.55(2.98,4.23)$ & $1.42(1.22,1.65)$ \\
& 2 & $1.32(1.18,1.47)$ & $1.55(1.28,1.87)$ & $1.22(1.03,1.43)$ \\
& 3 & $1.12(0.99,1.26)$ & $1.38(1.12,1.71)$ & $1.06(0.87,1.29)$ \\
& 4 & $1.04(0.91,1.19)$ & $1.14(0.91,1.44)$ & $1.10(0.89,1.36)$ \\
\hline
\end{tabular}

${ }^{1}$ Female was the reference category for gender and parity $5+$ was the reference category for dam parity..

The log of the odds of an assisted calving increased linearly by $0.21 \pm 0.01(P<0.001)$ per unit increase in EBV for direct calving difficulty (Table 4$)$. The association between EBV for direct calving difficulty and the likelihood of an assisted calving differed $(P<0.001)$ by cow parity, with a greater association in younger dams (Table 5). The $\log$ of the odds of an assisted calving increased linearly by $0.14 \pm 0.02$ per unit increase in EBV for maternal calving difficulty (Table 4) but did not differ by dam parity. In this study a weak to moderate negative correlation $(-0.20)$ existed between the EBV for direct and maternal calving dystocia, signifying that genetically easier calving bulls were used on cows that were prone to difficult calving.

The log of the odds of a dystocia increased linearly by $0.24 \pm 0.01(P<0.001)$ per unit increase in EBV for direct calving difficulty (Table 4$)$ but the association differed $(P=$ $0.005)$ by dam parity with the strength of the association weakening as parity increased (Table 5). The log of the odds for calving dystocia increased by $0.17 \pm 0.02(P<$ $0.001)$ per unit increase in EBV for maternal calving difficulty (Table 4) and was consistent across dam parities.

The predicted probability of assisted calving or calving dystocia for a calf 1 genetic merit SD worse than the mean for direct calving difficulty, born to a first parity dam, was 40 and 38 percentage units (\% units) greater, respectively, compared to a calf 1 genetic merit SD better than the mean for calving difficulty. For a mature cow (i.e., $\geq 5$ parity) the predicted probability of assisted calving or calving dystocia was 14 and $10 \%$ units greater, respectively, for a calf with 1 genetic merit SD worse than the mean compared to a calf with 1 genetic merit SD better than the mean.

\section{Perinatal Mortality}

Males calves were 1.59 times $(P<0.001)$ more likely to be dead at birth compared to female calves (Table 3). First parity dams were 1.42 times $(P<0.001)$ more likely to have a dead calf compared to dams of parity 5 or greater (Table 3 ).

The log of the odds of a dead calf at birth increased linearly by $0.93 \pm 0.13(P<0.001)$ per unit increase in EBV
Table 4. Regression coefficient ( $b$; SE in parenthesis) of phenotypic performance on trait EBV as well as the associated $P$-value ${ }^{1}$

\begin{tabular}{lcc}
\hline \hline Trait & $b(\mathrm{SE})$ & $P$-value \\
\hline Age at first calving $_{\text {Calving interval }^{2}}$ & $0.32(0.15)$ & 0.03 \\
Survival $_{\text {Calving assistance }}{ }^{3}$ & $0.58(0.16)$ & 0.002 \\
$\quad 0.16(0.03)$ & $<0.001$ \\
$\quad$ Direct & $0.21(0.01)$ & \\
$\quad$ Maternal & $0.14(0.02)$ & $<0.001$ \\
Calving dystocia $^{3}$ & & $<0.001$ \\
$\quad$ Direct & $0.24(0.01)$ & \\
$\quad$ Maternal & $0.17(0.02)$ & $<0.001$ \\
$\quad$ Calf mortality & $0.93(0.13)$ & $<0.001$ \\
Weaning weight & & $<0.001$ \\
$\quad$ Direct & $1.75(0.09)$ & $<0.001$ \\
$\quad$ Maternal & $0.84(0.16)$ & $<0.001$ \\
\hline
\end{tabular}

${ }^{1}$ Regression coefficients for survival, calving assistance, calving dystocia, and calf mortality are on the logit scale.

${ }^{2}$ The association between EBV for calving interval and phenotypic calving interval differed by cow parity (results shown in Table 6); the main effect from the multiple regression model without the interaction term is shown here.

${ }^{3}$ The association between EBV for direct calving difficulty and the likelihood of calving assistance or calving dystocia differed by dam parity (result shown in Table 5); the main effect from the multiple regression model without the interaction term is shown here.

for calf mortality (Table 4). A calf 1 genetic merit SD better than the mean for mortality had a $7.4 \%$ unit lower predicted probability of being born dead compared to the same calf 1 genetic merit SD worse than the mean for mortality.

When calving difficulty score was included as a fixed effect in the model, the log of the odds of a dead calf at birth increased by $0.47 \pm 0.16(P=0.003)$ per unit increase in EBV for calf mortality indicating that the EBV for calf mortality is accounting for more than calf mortality attributable to a difficult calving.

\section{Reproductive Performance and Survival}

Age at first calving increased linearly by $0.32 \pm 0.15$ $(P=0.03)$ days per day increase in EBV for age at first calving (Table 4). However, if the dataset was reduced to spring calving herds only (i.e., $70 \%$ of cows calving between first January and first June; $n=3,922)$, age at first calving increased by $0.60 \pm 0.21 \mathrm{~d}(P=0.004)$ per unit increase in EBV for age at first calving.

First parity cows were 3.08 times $(95 \%$ confidence interval: 2.75 to $3.45 ; P<0.001)$ more likely to survive to the subsequent lactation compared to cows of parity 5 or greater. The log of the odds of a cow surviving to next lactation increased linearly by $0.16 \pm 0.03(P<0.001)$ per unit increase in EBV for cow survival (Table 4). A cow 1 genetic merit SD better than the mean for survival had a $3.2 \%$ units greater predicted probability of surviving to the next lactation compared to the similar cow 1 genetic 
Table 5. The association between EBV for direct calving difficulty and the log of the odds (SE in parenthesis) for calving assistance and calving dystocia in different dam parities

\begin{tabular}{lcc}
\hline \hline Dam parity & Calving assistance & Calving dystocia \\
\hline 1 & $0.33(0.01)$ & $0.35(0.02)$ \\
2 & $0.16(0.01)$ & $0.22(0.02)$ \\
3 & $0.16(0.01)$ & $0.21(0.02)$ \\
4 & $0.16(0.01)$ & $0.17(0.02)$ \\
$5+$ & $0.16(0.01)$ & $0.15(0.02)$ \\
\hline
\end{tabular}

merit SD worse than the mean for survival. When EBV for survival in the model was substituted with EBV for calving interval the log of the odds for cow survival decreased by $-0.03 \pm 0.01(P=0.0006)$ per unit increase in EBV for calving interval, implying that genetic selection for improved fertility also improved survival.

Calving interval increased by, on average, $0.58 \pm 0.16$ $(P=0.002)$ days per day increase in EBV for calving interval (Table 4). However, the association between EBV for calving interval and phenotypic calving interval differed by parity with a greater effect in pluriparae (Table 6); mean calving interval also differed by parity (Table 6). When the dataset was reduced to spring calving herds only (i.e., $70 \%$ of cows calving between first January and first June; $n=$ 20,050), phenotypic calving interval increased by $0.51 \pm$ $0.21 \mathrm{~d}(P<0.001)$ per increase in EBV for calving interval. The association between EBV for calving interval and phenotypic calving interval for spring calving herds also differed by parity $(P<0.001$; Table 6$)$.

\section{Weaning Weight}

The association between age at weaning and weaning weight differed by gender $(P<0.001)$, with males growing faster ( $1.06 \pm 0.01$ per day of age) than females $(0.89 \pm 0.01$ per day of age $)$. Phenotypic weaning weight increased linearly, on average, by $1.75 \pm 0.09 \mathrm{~kg}$ per $\mathrm{kg}$ increase in EBV for direct weaning weight $(P<0.001)$ and did not differ by dam parity. Weaning weight increased by $0.84 \pm 0.16 \mathrm{~kg}$ per $\mathrm{kg}$ increase in EBV for maternal weaning weight $(P<0.001$; Table 4$)$ and did not differ by dam parity. A negative correlation $(-0.18)$ existed between EBV for direct weaning weight and EBV for maternal weaning weight.

\section{DISCUSSION}

Genetic variation is known to contribute significantly to phenotypic differences among individuals across a range of traits. The relative contribution of additive genetic variation to differences in phenotypic performance, coupled with knowledge of systematic environmental effects and relationships among animals, is used in the ge-
Table 6. Phenotypic mean and SD as well as regression coefficient ( $b$; SE in parenthesis) of phenotypic calving interval performance on calving interval EBV in different parities in 1) all herds or 2) spring calving herds only

\begin{tabular}{lccccccc}
\hline \hline \multirow{2}{*}{$\begin{array}{l}\text { Cow } \\
\text { parity }\end{array}$} & \multicolumn{4}{c}{ All herds } & & \multicolumn{3}{c}{ Spring calving herd } \\
\cline { 2 - 4 } \cline { 6 - 8 } & Mean & SD & $b($ SE $)$ & & Mean & SD & $b($ SE $)$ \\
\hline 1 & 391 & 65 & $-0.05(0.25)$ & & 383 & 60 & $-0.40(0.33)$ \\
2 & 377 & 58 & $0.89(0.26)$ & & 370 & 51 & $0.71(0.33)$ \\
3 & 374 & 55 & $1.36(0.27)$ & & 369 & 50 & $1.73(0.35)$ \\
4 & 372 & 53 & $1.37(0.30)$ & & 367 & 46 & $1.57(0.38)$ \\
$5+$ & 374 & 53 & $1.05(0.23)$ & & 369 & 46 & $0.77(0.30)$ \\
\hline
\end{tabular}

netic evaluation process to estimate the genetic merit (i.e., EBV) of individuals from the available phenotypic performance data. These EBV are used by producers to identify the genetically elite animals as candidates for subsequent generations. Therefore, the accuracy of these evaluations is fundamental to realizing the benefits of using such information in breeding decisions. Skepticism among producers sometimes exists on the accuracy of these evaluations in commercial production systems. This is particularly true for maternal characteristics. Results from this study show that selection for favorable genetic attributes will result in favorable improvements in performance.

\section{Population Statistics and Nongenetic Effects}

Irish beef production systems are seasonal to maximize the exploitation of the lower cost grazed grass in the diet. The majority (i.e., 67\%) of cows calve in the months of February to May (Berry and Evans, 2014) coinciding with the initiation of grass growth. Calves are weaned some 8 mo later coinciding with the decline in grass growth rates; $54 \%$ of Irish weanling animals are sold between mid August and mid October (McHugh et al., 2010). Therefore, excellent reproductive performance in the beef cow, in combination with good calf growth, is paramount to a profitable beef grazing production system. Such systems therefore require cows to calve for the first time at approximately 24 mo of age, have a calving interval of $365 \mathrm{~d}$, produce sufficient yield of milk, and survive for a long time in the herd. The mean cow performance of the population in this study, consistent with that observed in an analysis of a larger dataset of Irish beef cows (Berry and Evans, 2014), was suboptimum, substantiating the necessity to improve the genetic merit of the cows (simultaneous with improved management). Improved genetic merit for reproductive performance of cows provides a greater opportunity for producers to calve cows earlier in the season maximizing the quantity of grazed grass in the diet but also obtaining greater weaning weights at the time of sale, thereby increasing profitability. Furthermore, improved genetic 
merit for survival reduces the replacement rate required thereby increasing profit but, also, weanling animals from older mature cows are more valuable (McHugh et al., 2010), some of which is due to greater weaning live weight (McHugh et al., 2010), most likely due to greater milk yields in older animals (Elzo et al., 1987; Holland and Odde, 1992). This is further compounded by the ability to use more muscular and better conformed bulls on older mature cows, which are less prone to calving difficulty as observed in the present study after accounting for the genetic merit of the mating bull used. Although management has a large influence on phenotypic performance, having superior genetic merit for maternal traits, at least, provides a good foundation on which management can influence the eventual phenotype.

The greater calving assistance or dystocia for male calves has been documented many times previously in both beef and dairy cows (Meijering, 1984; Berry et al., 2007; Lombard et al., 2007) including in Irish dairy cows (Mee et al., 2011). Similarly, greater perinatal mortality in male calves has been reported for Irish cattle populations (Mee et al., 2008) and elsewhere (Steinbock et al., 2003; Eriksson et al., 2004; Heins et al., 2006). The increased risk of calving difficulty or perinatal mortality in primiparae has been well established in cattle (Steinbock et al., 2003; Berry et al., 2007; Mee et al., 2008).

\section{Association between Estimated Genetic Merit and Performance}

The measures of genetic merit used in this study were EBV equivalents. Therefore, a 1 unit change in EBV is expected to result in, on average, a 1 unit change in phenotypic performance where the unit of measurement is the same. Genetic evaluations for cow survival and calving performance are undertaken using a linear mixed model so the expected absolute relationship with the log of the odds is more complicated than a one-to-one relationship. A 1 unit difference in cow survival means a $1 \%$ unit difference in survival from one lactation to the next; similarly, for calving difficulty, a 1 unit difference is equivalent to a $1 \%$ unit difference in calving difficulty.

Across all traits, the direction of the associations between phenotype and EBV concurred with expectations although the incremental change in the phenotype per unit change in EBV was not always as large as expected. This was particularly true for the low heritability trait of calving interval; heritability of calving interval in Irish beef cows is 0.02 (Berry and Evans, 2014). Low heritability means that a small proportion of the variation among animals is due to measurable additive genetic effects (i.e., EBV) with the remaining variation attributable to nonadditive genetic effects, systematic environmental effects (e.g., herd management), permanent environmental effects, and residual effects, among others. Interestingly, for calving interval, parity of the dam had a large influence on the strength of the relationship between the EBV and the phenotypic performance. With the exception of the first parity cows, a 1 unit change in EBV for calving interval resulted in, approximately, a 1 unit change (i.e., the theoretical expectation) in phenotypic performance. It is a common practice on Irish beef farms to manage first parity cows differently to older parity cows; heifers are commonly bred earlier than the main herd and therefore calve earlier. However, subsequent mating of the first parity cows coincides with the mating of older parity cows, hence increasing the calving interval of first parity cows (391 d in the present study) compared to older parity cows (372 to $377 \mathrm{~d}$ in the present study). The weak association between genetic merit and phenotypic performance for calving interval in first parity cows may be partly explained by the management practices of first parity cows on Irish beef farms and the inability of genetic differences among individuals for calving interval to be fully exploited. Nonetheless, what the present study clearly does show, in older cows at least, is that considerable improvements in fertility performance can be achieved through improving herd genetic merit, even for this low heritability trait.

Age at first calving is highly heritable (Berry and Evans, 2014) and a $1 \mathrm{~d}$ difference in EBV for age at first calving was only associated with a $0.32 \mathrm{~d}$ phenotypic difference. This is likely in part to be influenced by the seasonal calving system in Ireland. If a heifer is not bred in time to calve at $2 \mathrm{yr}$ of age within the calving season, then she is generally not bred until the following breeding season. Furthermore, many Irish producers make a conscious decision a priori to calve all heifers at $3 \mathrm{yr}$ of age rather than $2 \mathrm{yr}$ of age also reducing the strength of the relationship; a similar trend in the management of Irish dairy heifers for age at first calving has been reported previously (Berry and Cromie, 2009).

Predicted probabilities calculated for the binary traits (calving assistance, calving dystocia, calf mortality, and cow survival) in the present study were based on the comparison of animal's divergent in genetic merit for a given trait. A difference in EBV for calf mortality of 5 units (i.e., difference between \pm 1 EBV SD from the mean EBV) manifested itself as a difference in predicted probability of $7.4 \%$ units. A difference in $2 \%$ units in cow survival (i.e., difference between $\pm 1 \mathrm{EBV}$ SD from the mean EBV) was associated with a $3.2 \%$ unit difference in predicted probability of survival. For calving assistance and dystocia for first parity cows a difference in $5 \%$ units (i.e., difference between $\pm 1 \mathrm{EBV}$ SD from the mean EBV) corresponded to a difference in the predicted probability of 40 and $38 \%$, respectively. The strong interaction between parity and EBV for 
calving difficulty may explain some of the differences since when the predicted probabilities were calculated from mature cows (i.e., parity 5 or greater), the predicted probabilities were more in line with the expected differences based on the published EBV. Nonetheless, these results do highlight that considerable improvements can be achieved by choosing the appropriate parents of the next generation; results presented here are not based on the comparison of animals extreme for genetic merit so they are therefore relatively easily achievable.

Calving difficulty and calf mortality are influenced by similar environmental factors and both traits are strongly interrelated in both beef and dairy cattle (Meijering, 1984; Gregory et al., 1991; Eriksson et al., 2004). Previous studies have shown that more than half of stillborn calves did not experience any calving difficulty (Berger et al., 1992; Steinbock et al., 2003; Eriksson et al., 2004); when calving difficulty was included as a fixed effect in the calf mortality multiple regression model in the present study, the regression coefficient on EBV for calf mortality decreased by approximately $50 \%$ of its original value thereby indicating that EBV for calf mortality is still associated with calf mortality independent of calving dystocia. Estimated breeding value for calf mortality is estimated in the national genetic evaluations using a univariate model that does not include calving difficulty.

Estimated genetic merit for direct calving difficulty is the additive genetic merit of the calf itself, which influences its birth and includes animal characteristics such as the body size and shape of the calf. Estimated genetic merit for maternal calving difficulty is the additive genetic merit of the dam, which influences the birthing process and may include characteristics such as dam pelvic width. Similarly, direct weaning weight represents the additive genetic merit of the calf to achieve a good weaning weight (i.e., growth rate), while the maternal weaning weight represents the additive genetic merit of the dam to facilitate the calf in achieving a good weaning weight; maternal weaning weight is generally thought to reflect the milk yield of the cow. Minogue et al. (2013) documented a moderate to strong correlation $(0.56)$ between maternal weaning weight and measured milk yield in 105 first parity beef cows on an Irish research herd. In Ireland, both direct and maternal genetic effects are estimated simultaneously in the genetic evaluation process. What is clear from the present study is that both phenomena have an additive effect on the resulting phenotype of the calf. Weaning weight increased by $1.75 \mathrm{~kg}$ per unit increase in EBV for direct weaning weight and a further $0.84 \mathrm{~kg}$ per unit increase in EBV for maternal weaning weight. Similarly, the log of the odds of dystocia increased by 0.24 and 0.17 per unit increase in direct and maternal calving difficulty, respectively. Considerable gains, therefore, in both weaning weight and calving performance can be achieved if terminal sires with good genetic merit for the direct traits are mated to cows with good genetic merit for both the direct and maternal traits. It is important to remember that half of the direct effects of a calf originate from the dam so therefore the dam must excel in both direct and maternal characteristics.

The lower heritability for the maternal component for weaning weight and the calving traits (Table 2), coupled with the longer time horizon to obtain phenotypes on progeny of bulls, means that obtaining more accurate estimates of genetic merit for maternal effects will be more demanding. Negative covariances have also been documented to exist between direct and maternal components (Meyer, 1997; Bennett and Gregory, 2001; Eriksson et al., 2004), implying animals excelling in both characteristics can be difficult to acquire thereby further compounding the difficulty in achieving genetic gain in maternal traits. This study nevertheless shows the benefit of putting effort in achieving genetic gain in such maternal traits to increase herd performance; increased accuracy of selection will be best achieved through a well-structured breeding scheme design.

Calving difficulty has been shown to be influenced by different factors in first versus later parity cows (Eriksson et al., 2004). For heifers, the critical factor in determining calving difficulty is calf size to pelvic size ratio, whereas for older cows, factors such as malpresentation of the calf, weak labor, and insufficient dilatation of the cervix are more likely to lead to calving difficulty (Meijering, 1984). Such factors may provide a biological explanation for the significant interactions between dam parity number and the EBV for calving difficulty that were obtained in the present study for both calving assistance and dystocia.

In conclusion, results from this study clearly show that genetic selection for improved maternal performance will materialize in improvements in phenotypic performance, despite the low heritability of many of the maternal traits. Therefore, a breeding policy to improve maternal performance should constitute an integral part of any strategy designed to increase herd profitability within the beef sector.

\section{LITERATURE CITED}

Bennett, G. L., and K. E. Gregory. 2001. Genetic (co)variances for calving difficulty score in composite and parental populations of beef cattle: I. Calving difficulty score, birth weight, weaning weight and postweaning gain. J. Anim. Sci. 79:45-51.

Berger, P. J., A. C. Cubas, K. J. Koehler, and M. H. Healey. 1992. Factors affecting dystocia and early calf mortality in Angus Cows and Heifers. J. Anim. Sci. 70:1775-1788.

Berry, D. P., and A. R. Cromie. 2009. Association between age at first calving and subsequent performance in Irish spring calving Holstein-Friesian dairy cows. Livest. Sci. 123:44-54.

Berry, D. P., and R. D. Evans. 2014. Genetics of reproductive performance in seasonal calving beef cows and its association with performance traits. J. Anim. Sci. (in press). 
Berry, D. P., J. M. Lee, K. A. Macdonald, and J. R. Roche. 2007. Body condition score and body weight effects on dystocia and stillbirths and consequent effects on postcalving performance. J. Dairy Sci. 90:4201-4211.

Berry, D. P., F. E. Madalena, A. R. Cromie, and P. R. Amer. 2006. Cumulative discounted expressions of dairy and beef traits in cattle production systems. Livest. Prod. Sci. 99:159-174.

Brown, M. A., S. W. Coleman, and D. L. Lalman. 2005. Relationship of sire expected progeny differences to milk yield in Brangus cows. J. Anim. Sci. 83:1194-1201.

Campion, B., M. G. Keane, D. A. Kenny, and D. P. Berry. 2009. Evaluation of estimated genetic merit for carcass weight in beef cattle: Live weights, feed intake, body measurements, skeletal and muscular scores, and carcass characteristics. Livest. Sci. 126:87-99.

Clarke, A. M., M. J. Drennan, M. McGee, D. A. Kenny, R. D. Evans, and D. P. Berry. 2009. Intake, live animal scores/measurements and carcass composition and value of late-maturing beef and dairy breeds. Livest. Sci. 126:57-68.

Coleman, J., D. P. Berry, K. M. Pierce, A. Brennan, and B. Horan. 2010. Dry matter intake and feed efficiency profiles of 3 genotypes of Holstein-Friesian within pasture-based systems of milk production. J. Dairy Sci. 93:4318-4331.

Crump, R. E., N. R. Wray, R. Thompson, and G. Simm. 1997. Assigning pedigree beef performance records to contemporary groups taking account of within-herd calving patterns. J. Anim. Sci. 65:193-198.

Diaz, C., D. R. Notter, and W. E. Beal. 1992. Relationship between milk expected progeny differences of polled Hereford sires and actual milk production of their crossbred daughters. J. Anim. Sci. 70:396-402.

Elzo, M. A., R. L. Quaas, and E. J. Pollak. 1987. Effects of age of dam on weight traits in the Simmental population. J. Anim. Sci. 64:992-1001.

Eriksson, S., A. Nasholm, K. Johansson, and J. Philipsson. 2004. Genetic parameters for calving difficulty, stillbirth, and birth weight for Hereford and Charolais at first and later parities. J. Anim. Sci. 82:375-383.

Evans, R. D., T. Pabiou, A. Cromie, F. Kearney, R. Veerkamp, and P. Amer. 2007. Genetic improvement in the Irish suckler beef herd: Industry expectation and experience so far. In: Proc. INTERBULL Technical Workshop, March 9-10, 2007, Paris. Bulletin 36, p. 7.

Evans, R. D., T. Pabiou, A. Cromie, F. Kearney, R. Veerkamp, and P. Amer. 2008. Developments in national and international beef evaluations: Some experiences from Ireland. In: Proc. INTERBULL Meeting, June 16-19, 2007, Niagara Falls, NY. Bulletin 38, p. 13.

Evans, R. D., T. Pabiou, A. Cromie, F. Kearney, R. Veerkamp, and P. Amer. 2009. Multi-breed genetic evaluation for docility in Irish suckler beef cattle. In: Proceedings of the INTERBULL Meeting, August 21-23, 2009, Barcelona, Spain. Bulletin 40, p. 127.

Gregory, K. E., L. V. Cundiff, and R. M. Koch. 1991. Breed effects and heterosis in advanced generations of composite populations for birth weight, birth date, dystocia, and survival as traits of dam in beef cattle. J. Anim. Sci. 69:3574-3589.

Heins, B. J., L. B. Hansen, and A. J. Seykora. 2006. Calving difficulty and stillbirths of pure Holsteins versus crossbreds of Holstein with Normande, Montbeliarde and Scandinavian Red. J. Dairy Sci. 89:2805-2810.
Holland, M. D., and K. G. Odde. 1992. Factors affecting calf birth: A review. Theriogenology 38:769-798.

Lidauer, M., K. Matilainen, E. Mantysaari and I. Stranden. 2011. Mixed Model Equations Solver - Mix99. https://portal.mtt.fi/ portal/page/portal/mtt en $/ \mathrm{mtt} /$ about/researchunits/bel/biometricalgenetics/software/MiX99/documentation/7D327F881511 C24EE040A8C0033C4560. Accessed Feb. 24, 2014.

Lombard, J. E., F. B. Garry, S. M. Tomilinson, and L. P. Garber. 2007. Impacts of dystocia on health and survival of dairy calves. J. Dairy Sci. 90:1751-1760.

MacNeil, M. D. 2003. Genetic evaluation of an index of birth weight and yearling weight to improve efficiency of beef production. J. Anim. Sci. 81:2425-2433.

Marshall, D. M., and M. B. Long. 1993. Relationship of beef sire expected progeny differences to maternal performance of crossbred daughters. J. Anim. Sci. 71:2371-2374.

McHugh, N., A. G. Fahey, R. D. Evans, and D. P. Berry. 2010. Factors associated with selling price of cattle at livestock auctions. Animal 8:1378-1389.

Mee, J. F., D. P. Berry, and A. R. Cromie. 2008. Prevalence of, and risk factors associated with, perinatal calf mortality in pasturebased Holstein-Friesian cows. Animal 4:613-620.

Mee, J. F., D. P. Berry, and A. R. Cromie. 2011. Risk factors for calving assistance and dystocia in pasture-based Holstein-Friesian heifers and cows in Ireland. Vet. J. 187:189-194.

Meijering, A. 1984. Dystocia and stillbirth in cattle - A review of causes, relations and implications. Livest. Prod. Sci. 11:143-177.

Meyer, K. 1997. Estimates of genetic parameters for weaning weight of beef cattle accounting for direct-maternal environmental covariances. Livest. Prod. Sci. 52:187-199.

Miller, S. P., and J. W. Wilton. 1999. Genetic relationships among direct and maternal components of milk yield and maternal weaning gain in a multibreed breed herd. J. Anim. Sci. 77:1155-1161.

Minick, J. A., D. S. Buchanan, and S. D. Rupert. 2001. Milk production of crossbred daughters of high- and low-milk EPD Angus and Hereford bulls. J. Anim. Sci. 79:1386-1393.

Minogue, D., A. R. Cromie, M. McGee, W. Minchin, and N. McHugh. 2013. The relationship between milk yield and predicted transmitting ability for maternal weaning weight across four cow breed types In: Irish Agricultural Research Forum. This is published by the Irish Grassland and Animal Production Association. ISBN 1-84170-586-1. p. 65.

Ramsbottom, G., A. R. Cromie, B. Horan, and D. P. Berry. 2012. Relationship between dairy cow genetic merit and profit on commercial spring calving dairy farms. Animal 6:1031-1039.

Steinbock, L., A. Nasholm, K. Johansson, and J. Philipsson. 2003. Genetic effects on stillbirth and calving difficulty in Swedish Holsteins at first and second calving. J. Dairy Sci. 86:2228-2235.

Thrift, F. A., and T. A. Thrift. 2006. Review: Expected versus realized progeny differences for various beef cattle traits. Prof. Anim. Sci. 22:413-423. 